\title{
Layoff announcements and intra-day market reactions
}

\author{
Santiago Velásquez ${ }^{1} \cdot$ Juho Kanniainen² ${ }^{2}$ \\ Saku Mäkinen² $\cdot$ Jaakko Valli $^{2}$
}

\begin{abstract}
This paper examines investor intra-day reactions related to two types of layoff announcements, the first one at the start of layoff negotiations and the other at the final layoff decisions. We provide statistically significant evidence that, on average, investors have strongly negative reaction to layoff negotiations within the first $10 \mathrm{~min}$. However, we also provide strong evidence that the first negative reaction is reversed by an upward post-drift in aggregated cumulative abnormal returns in the following hours, perhaps because markets need hours to process such unpredictable and complex information and its consequences-even if their first reaction was strong and immediate. Moreover, on the aggregated level, final layoff announcements do not generally convey information that is exceptionally useful to investors, except when reactions to associated initial announcements have not been statistically significant. Importantly, our analysis demonstrates the importance of the use of intra-day data: The reactions, which can be strong but short-lived, are identifiable with intra-day data only. Finally, we find that intra-day reactions cannot be explained by various company background characteristics, such as the number of employees, sales, profitability, and assets/liabilities ratio.
\end{abstract}

Keywords Layoff Announcements $\cdot$ Abnormal return $\cdot$ Stock markets

JEL Classification G19 · M54 · O15 · O16

Juho Kanniainen

juho.kanniainen@tut.fi

1 UniAndes School of Management (UASM), Universidad de Los Andes, Bogotá, Colombia

2 Department of Industrial Management, Tampere University of Technology, P.O. Box 541, 33101 Tampere, Finland 


\section{Introduction}

Event studies measure "the impact of a specific event on the value of a firm" (MacKinlay 1997, p. 13) and are commonly used to study the effects of layoff announcements on market returns. Although event studies can be traced back to the 1930s (e.g., Dolley 1933), the first event study focused on evaluating the effects of layoff announcements on stock prices was published in 1991 (see Worrell et al. 1991). The results of most studies indicate negative stock price reactions to layoff announcements. Some studies, however, provide evidence of positive responses (e.g., Brookman et al. 2007). Various studies also report mixed results, highlighting the relevance of the reasons for the layoff (e.g., Lin and Rozeff 1993; Chalos and Chen 2002) or the market conditions at the moment of the announcement (Farber and Hallock 2009; Marshall et al. 2012). One potential reason that explains the existing mixed findings can be due to the sampling frequency of data. In particular, the extant literature commonly analyzes abnormal returns (ARs) or cumulative abnormal returns (CARs) on daily data. However, the use of daily data brings problems that intra-day data analysis may alleviate (see, for example, Lee et al. 1993). First, and most importantly, a daily data event window provides no information on the intra-day behavior of stock prices around the events, and these immediate market reactions cannot be gauged by using only closing prices. For example, Lee et al. (1993, p. 354) argue that "since most of the price reaction to a news event occurs within minutes after the announcement, closing quotes may not reflect the announcement effect." Second, the use of daily data requires a longer estimation window that can bring problems due to time-varying volatility, that is heteroscedastic asset returns (see, e.g., Engle and Bollerslev 1986; Bollerslev et al. 1992). Moreover, because the use of daily returns requires long estimation windows, several unrelated events may falsify the results, especially if they are not spread over time. Importantly, intra-day data may allow the consideration of more than one layoff announcement per firm in a month.

Our paper contributes to the extant investigation of investor reactions to corporate layoffs, but instead of using daily data, we use intra-day data from the Helsinki Stock Exchange, which enables us to identify possible immediate market reactions (and in certain cases even subsequent reactions) and to analyze how such complex information is processed in the markets during the course of a day. Delayed reactions are of particular interest to us, and our paper focuses on answering how markets react to initial announcements and final decisions by assessing (i) if markets react to announcements immediately, (ii) if the reactions are positive or negative, (iii) what the magnitude and statistical significance of the reactions are, (iv) how markets post-process the announcements during the following hours, (v) what the relation between paired initial announcements and final decisions is in terms of returns, and (vi) if company background characteristics and market reactions are linked. We also provide an additional test by analyzing intra-day versus daily stock market reactions to layoff announcements.

The results of this paper, which are statistically significant, show that investors react strongly and negatively to initial announcements on the aggregated level and that the 
reaction occurs within the first 10 min after layoff negotiations have been announced. However, the immediate reaction then retracts by an upward post-drift in aggregated cumulative abnormal returns during the following hours, perhaps because markets need hours to process such unpredictable and complex information and its consequences, even if their first reaction was strong and immediate. We refer to this phenomenon as the "intra-day post-reversal effect". Moreover, our results included no significant reactions to the final announcement at the significance level of $1 \%$, suggesting that the final decisions have been partially predictable or perhaps known in advance. We further evaluated the pairs of initial announcements and their corresponding final decisions and gained weak evidence that if an initial announcement conveyed no useful information about the stock valuation (i.e., the market did not react significantly to the initial announcement), the associated decision may affect stock returns strongly. Additionally, our analysis demonstrates the importance of the use of intra-day data: The reactions, which can be strong but short-lived, are identifiable with intra-day data only. Furthermore, we found no statistical link between various company background characteristics (number of employees, net sales, operating profit, EBT, EBTR, assets/liabilities) and the magnitude or type (positive or negative) of reactions to either initial announcements or final decisions.

This paper contributes in various ways to the extant literature. First, this is the first study to evaluate the effect of employee downsizing announcements in stock exchange releases on market returns using intra-day market data, and therefore, it casts light on the immediate effects of layoff announcements. Importantly, we observe not only an immediate negative reaction but also a reversal effect on the aggregated level, which we consider the main result of this paper. Second, to our knowledge, our analysis of the pairs of initial announcements and final decisions is unique. Third, by drawing on a sample of 369 announcements of companies trading on the Helsinki Stock Exchange (OMXH), this is the first study to analyze the effects of layoff announcements on market returns in a Nordic context. Overall, this paper responds to the call for more research on downsizing and its consequences (Cascio et al. 1997; Datta et al. 2010).

The rest of the paper is organized as follows. The following section is a literature review and develops a hypothesis. The third and fourth sections discuss the data and methodology of the study. The fifth section reports results where we first analyze 10-min abnormal returns and cumulative abnormal returns on initial announcements and final decisions before performing an explanatory analysis of the relationship between initial announcements and the corresponding final decisions. We also perform an additional analysis to regress the abnormal returns against background information on companies' characteristics. The final section discusses the conclusions and limitations of the paper.

\section{Literature review and hypothesis development}

A layoff can be defined as a temporary or permanent termination of one or more employees from the payroll of an organization (Cornfield 1983, p. 504; Chen et al. 2001, p. 172). Other similar definitions include reductions in force, downsizing, 
downscoping, reduction in personnel, and workforce reduction. Whereas reductions in force "denote large, permanent, frequently reactive" layoffs, downsizing commonly signifies "a streamlining of operations" to improve a company's competitive position (De Meuse et al. 1994, p. 522). Furthermore, Lee (1997, p. 880) ${ }^{1}$ compares downsizing to downscoping and defines the latter as "the process through which firms reemphasize their core businesses." For this paper, we adopted Cornfield's definition (1983) and consider any termination of employment a layoff regardless of its magnitude.

The literature review by Datta et al. (2010) groups the antecedents of layoffs into two main categories, namely, environmental (e.g., economic environment and types of industries) and organizational factors (e.g., human resources policies and organizational strategies). As for consequences, layoffs may allow an organization to change its competitive position within the industry and fight financial distress (Lee 1997). In addition, improvement of profit margins and labor productivity after layoffs were noted in a study by Chen et al. (2001). Wayhan and Werner (2000) conclude that reductions in the workforce improve financial performance, particularly in the short term. However, according to Hillier et al. (2007, p. 469), downsizing leads only to a "marginal improvement" in company performance. Moreover, Cascio (1993) states that for many companies, layoffs do not result in increased profits. In fact, De Meuse et al. (2004) argue that after downsizing, a company will need several years to financially recover. In addition, studies show that a company's financial performance, in fact, deteriorates after layoffs (De Meuse et al. 1994). Other negative consequences include loss of valuable knowhow and triggering of negative attitudes, for example, increase in fear and a drop in motivation, morale, punctuality, and general satisfaction among the workers who are not laid off (Cascio 1993; Franz et al. 1998; Wayhan and Werner 2000; De Meuse et al. 2004).

Event study methodologies are applied in very different contexts, including marketing (see Corrado 2011), mergers and acquisitions (see Mentz and Schiereck 2008), law (MacKinlay 1997) and layoffs (see Elayan et al. 1998; Farber and Hallock 2009). MacKinlay (1997, p. 13) notes that in "the majority of applications, the focus is the effect of an event on the price of a particular class of securities in the firm, most often common equity." Event studies assume that changes in a firm's stock price reflect investor expectations of future performance after important strategic moves have been announced (Lee 1997; Nixon et al. 2004).

According to the existing literature, layoff announcements can result in positive, negative, or mixed stock price reactions. Investors may react positively to a layoff announcement if they perceive this action as improving company performance and generating a positive net present cash flow when comparing layoff and non-layoff scenarios (Elayan et al. 1998; Nixon et al. 2004). In particular, the market may react positively if investors view layoffs as a strategy for overcoming financial difficulties, as resulting from restructuring or consolidation, as a pure-efficiency cost-cutting action, as a measure to reorganize and ultimately reduce costs, as a

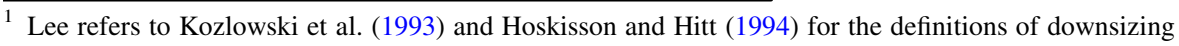
and downscoping.
} 
decision to control product prices to improve competitiveness, or as a way to increase sales, profitability, and firm value (Worrell et al. 1991; Lin and Rozeff 1993; Chatrath et al. 1995; Palmon et al. 1997). Moreover, the market may act neutrally if the layoff announcement conveys information that investors already know or if the perceived positive and negative aspects offset each other (Worrell et al. 1991; Chatrath et al. 1995). The results by Cascio et al. (1997) suggest that the total returns on the common stock of downsizing companies are better when compared to their industries. Other positive market responses are discussed in Wayhan and Werner (2000) and Brookman et al. (2007).

However, investors may perceive layoff announcements negatively if they contain bad news about a company's financial performance and if layoffs are perceived as defensive (i.e., as reactions to difficulties). Examples of negative news include declining sales, money losses, unexpected lower earnings, signals that the firm and/or its growth opportunities are in a more precarious state than previously thought, closure of plants or facilities, negative revision of future operating prospects, new information about adverse market conditions, or an insufficient layoff (Worrell et al. 1991; Lin and Rozeff 1993; Chatrath et al. 1995; Palmon et al. 1997; Elayan et al. 1998; Chen et al. 2001; Capelle-Blancard and Couderc 2006; Hillier et al. 2007). Negative market reactions have been observed in studies by Worrell et al. (1991), Lin and Rozeff (1993), Lee (1997), Elayan et al. (1998), Franz et al. (1998), Hallock (1998), Chen et al. (2001), Nixon et al. (2004), CapelleBlancard and Couderc (2006), and Hillier et al. (2007). Last, Goins and Gruca (2008) found that layoff announcements result in a negative but statistically nonsignificant market reaction.

Some scholars have noted mixed reactions depending on the time or market conditions upon the announcement. For example, Farber and Hallock (2009), who studied the period from 1970 to 1999 , found that whereas layoff announcements tend to result in negative stock price reactions, the reaction becomes less negative over time. Similarly, Chatrath et al.'s (1995) results suggest that investor reactions to layoff announcements changed from statistically significantly negative abnormal returns in the 1980s to statistically significant and positive returns in the period from 1991 to 1992. In addition, Marshall et al. (2012) found that markets reacted positively to layoff announcements during rising financial markets and negatively during the 2008 financial crisis. Mixed reactions may also depend on the reason given for the layoff. Palmon et al. (1997) conclude that whereas negative abnormal returns follow statements of declining demand, announcements of efficiency improvement tend to result in positive abnormal returns. Furthermore, Wertheim and Robinson (2000) argue that the market reacts differently depending on whether the layoff announcement signals financial distress or potential benefits. In line with this, the results by Chalos and Chen (2002) show that layoff announcements about plant closings resulted in slightly negative market reactions whereas those about strategic plans to refocus lines of business resulted in statistically significantly positive abnormal returns.

Consequently, given the far-reaching consequences associated with employee reduction and the expected market reaction to the first layoff announcement, we hypothesize regarding our research questions (i-iii) that. 
H1 The effect of initial announcements on stock prices is immediate and, on average, negative.

A layoff announcement is an unscheduled event, which "provides a signal to the market regarding the firm's current state as well as its future ability to compete effectively in the marketplace" (Nixon et al. 2004, p. 1122). Moreover, the relevant literature seems to acknowledge that markets react to announcements and not to actual layoffs (Worrell et al. 1991). Ferguson (2015, p. 322) notes that given the limitation of resources and cognitive constraints, investors "rely on the news to filter negative information." Ferguson (2015, p. 323) also notes that "investors overreact to highly visible news". Overall, announcements on layoffs can be informationally complex due to their multi-dimensional and partially soft character, and thus, it can be demanding to convert the information contents to Euros. Although "hard information" is easy to process (e.g., the information on income statements that follows a standardized template), "soft information" is often communicated in text, as in the case of layoff announcements. As Engelberg (2009) explains: "The textual data is qualitative, not easily comparable across firms (e.g., it is not easy to compare 'demand is weak' with 'management is inexperienced'), dependent upon who collects it (e.g., not everyone may agree that 'demand is weak'), and thus, difficult to interpret, store and pass on without loss of information." Consequently, given that investors may overreact to highly visible news (Ferguson 2015) and that such soft information is difficult to interpret (Engelberg 2009), we hypothesize the following regarding our research question (iv):

H2 Due to the informational complexity of initial layoff announcements, immediate reactions are reversed by financial markets in aggregated cumulative abnormal returns.

In addition, an increase in available information-for example corporate decisions, such as earnings announcements-reduces information asymmetry (Libby et al. 2002; Lee and O'Neill 2003; Ke 2013). Therefore, the period before an initial layoff announcement should carry more information asymmetry than the period after the announcement. According to De Meuse et al. (2004), most studies consider only the effects of the first layoff announcement because investors assume that companies will perform the announced layoffs. Moreover, because the information content of a final decision may either confirm or disconfirm the expected layoffs, it is unlikely to provide any surprising information. Consequently, we hypothesize the following regarding our research questions (i-iii):

H3 Final decisions do not result in a statistically significant market reaction at the aggregated level.

In addition to these three hypotheses, we perform an explanatory analysis of the relationship between initial announcements and corresponding final decisions to answer question (v).

Finally, previous studies have analyzed the relationship between various company background characteristics (e.g., financial data, number of employees, 
industry type) and layoff announcements. According to Datta et al. (2010), relationships have been found between layoff announcements and other variables, including economic conditions, industry deregulation, industry type, financial performance, market performance, firm productivity, firm size, market share, and reputation. Therefore, regarding question (vi), our last hypothesis is formulated as follows:

H4 The data on the Profitability, Change in Profitability, Company Size, and Change in Company Size company characteristics explain the sign and size of the reaction.

In testing the last hypothesis, our paper is in line with previous studies that analyze the relationships between firm characteristics and market returns.

\section{Data}

Our data consists of company stock exchange announcements and intra-day stock price data (both provided by NASDAQ OMX Helsinki), and information on company backgrounds drawn mainly from published annual reports. Stock releases were collected from internet pages of the Finnish commercial newspaper Kauppalehti (www.kauppalehti.fi) provides freely available stock and press releases of all publicly owned companies. In our analysis, there is one announcement time-stamp for each event, where the first time-stamp is always applied. However, we considered only stock releases in this study because the content of press releases is commonly known to the public well before the release is published (sometimes several days in advance). As a result of this decision, our sample did not include any layoff announcements of the company Nokia because all of their un-confounded layoff announcements during the analysis period were published in press releases. The exclusion of press releases that are not immediately published after the decision has become public is crucial in order to spot immediate reactions with intra-day data. Overall, non-delayed news announcements with fresh time-stamps are the basis of our data sample.

Our research period ranges from January 1, 2006 to December 31, 2010, and the raw data comprised 20,816 stock exchange announcements published by the companies listed on NASDAQ OMX Helsinki. We identified 404 layoff announcements from 80 companies during the research period. We deleted 35 announcements with confounding information, released at non-trading hours or containing intra-day market data on poor liquidity. As a result, our final sample consisted of 369 layoff announcements. Importantly, these intra-day data events came with precise time stamps, which allowed us to analyze immediate reactions to the layoff announcements. Thus, because we did not use multiple-day cumulative abnormal returns, our analysis was not subject to possible confounding events.

Moreover, Kauppalehti stock releases include announcements on the initiation of employee negotiations and the final decisions with exact time stamps (up to the second). Our final sample consisted of 176 initial announcements and 193 final decision announcements. Our initial announcements can be classified into two main 
categories: first, announcements explicitly disclosing the initiation of employee negotiations and, second, those reporting future layoffs. We identified 148 cases of the former and 28 cases of the latter. Layoff announcements (initial and final) typically specify the number and type of (temporal or permanent) and the reasons for layoffs. thus, if they were explicitly stated, we compiled these characteristics.

The intra-day high-frequency stock price (trade) data, provided by NASDAQ, covers the dates between January 2006 and December 2010. Our abnormal return calculation measured the deviation of an individual stock price from the market index, that is OMXHPI, which is a capitalization-weighted price index that follows all firms listed on NASDAQ OMX Helsinki. The index follows changes in the general investment environment and is not dependent on the volatility of a single firm's share price or changes in a single sector price. In addition to market index information, we acquired from Nasdaq all stock market transactions on the NASDAQ OMX Helsinki over the five-year research period. The data included all completed transactions during the period together with transaction-specific information, such as number of shares, price, and time of transaction. The total number of individual stock transactions was $68,827,956$.

The data is available every second, but we applied 10-min intervals to eliminate the effects of micro-structure noise (Aït-Sahalia et al. 2005). Compared to the existing literature on event studies that typically rely on daily closing prices, this stock market data is very accurate and rich with almost 500 daily observations. This is important in analyzing the length of the investors' reaction time concerning layoff announcements and the investors' processing of the information during the announcement day. The estimation window was 510 steps long with a step size of $10 \mathrm{~min}$, which is about 10 trading days. Therefore, instead of using two-year daily data in the estimation windows, with intra-day data we obtained the same number of observations in a 10-day window. This lessens markedly the effects of confounding events and heteroscedasticity (time-varying volatility and correlation).

Finally, most of our data on background company information was obtained from the companies' published annual reports. This background information included the number of employees, net sales, operating profit, EBIT, net profit, and total assets over a six-year period from 2005 to 2010.

\section{Method}

Event studies typically use a market model, where the return of security $i$ is regressed against the return on the market portfolio $R_{m t}$ :

$$
R_{i, t}=\alpha_{i}+\beta_{i} R_{m, t}+\epsilon_{i t},
$$

where $\alpha_{i}$ and $\beta_{i}$ are constants. An alternative model is a constant mean model, for which

$$
R_{i, t}=\alpha_{i}+\epsilon_{i t}
$$


where $\alpha_{i}$ is a constant. As pointed out by Mucklow (1994), a constant mean model is superior to a market model when relying on intra-day data. ${ }^{2}$ For a robustness check, we used constant mean and market portfolio return models, and because we obtained very similar results by using intra-day data, only the results for the constant mean model are reported.

The estimation period is from $T_{0}+1$ to $T_{1}$ with $L_{1}=T_{1}-T_{0}$, and the event window is from $T_{1}+1$ to $T_{2}$ with $L_{2}=T_{2}-T_{1}$. We used the same notation as Campbell et al. Let $\mathbf{R}_{i}=\left[R_{i, T_{0}+1}+\cdots+R_{i, T_{1}}\right]^{\prime}$ be an $\left(L_{1} \times 1\right)$ vector, $\mathbf{X}_{i}=\left[\mathbf{i}, \mathbf{R}_{m}\right]$ be an $\left(L_{1} \times 2\right)$ matrix with a vector of ones in the first column and market returns $\mathbf{R}_{m}=\left[R_{m, T_{0}+1}+\cdots+R_{m, T_{1}}\right]^{\prime}$ in the second column, and $\boldsymbol{\theta}_{i}=\left[\alpha_{i} \beta_{i}\right]^{\prime}$ be a $(2 \times 1)$ vector. Then the ordinary least squares estimators are

$$
\hat{\boldsymbol{\theta}}_{i}=\left(\mathbf{X}_{i}^{\prime} \mathbf{X}_{i}\right)^{-1} \mathbf{X}_{i}^{\prime} \mathbf{R}_{i}, \quad \hat{\sigma}_{\epsilon_{i}}^{2}=\frac{1}{L_{1}-2} \hat{\epsilon}_{i}^{\prime} \hat{\epsilon}_{i}, \quad \hat{\epsilon}_{i}=\mathbf{R}_{i}-\mathbf{X}_{i} \hat{\boldsymbol{\theta}}_{i}
$$

When parameter estimates $\boldsymbol{\theta}_{i}$ are applied to the $\left(L_{2} \times 1\right)$ returns from the event window, the estimate for the abnormal return vector is $\hat{\epsilon}_{i}^{*}=\mathbf{R}_{i}^{*}-\mathbf{X}_{i}^{*} \hat{\theta}_{i}$, where $\mathbf{R}_{i}^{*}=\left[R_{i, T_{1}+1}+\cdots+R_{i, T_{2}}\right]^{\prime}$ is an $\left(L_{2} \times 1\right)$ returns vector from the event window, and $\mathbf{X}_{i}^{*}=\left[\mathbf{i}, \mathbf{R}_{m}^{*}\right]$ is an $\left(L_{2} \times 2\right)$ matrix with a vector of ones in the first column and market returns $\mathbf{R}_{m}^{*}=\left[R_{m, T_{1}+1}+\cdots+R_{m, T_{2}}\right]^{\prime}$ in the second column. Then, as shown in Campbell et al. (1998), the covariance matrix $\mathbf{V}_{i}$ is $\mathbf{V}_{i}=$ $\hat{\sigma}_{\epsilon_{i}}^{2}\left(\mathbf{I}+\mathbf{X}_{i}^{*}\left(\mathbf{X}_{i}^{\prime} \mathbf{X}_{i}\right)^{-1} \mathbf{X}_{i}^{* \prime}\right)$, wherein $\mathbf{I}$ is the $\left(L_{2} \times L_{2}\right)$ identity matrix. $^{3}$

Under $\mathrm{H}_{0}$, the null hypothesis is $\epsilon_{i}^{*} \sim N\left(0, \mathbf{V}_{i}\right)$. Therefore, to test $\mathrm{H}_{0}$, let us denote the standardized cumulative abnormal return of stock $i$ from $\tau_{1}$ to $\tau_{2}$ as

$$
\widehat{S C A} R_{i,\left(\tau_{1}, \tau_{2}\right)}=\widehat{C A R}_{i,\left(\tau_{1}, \tau_{2}\right)} / \hat{\sigma}_{i,\left(\tau_{1}, \tau_{2}\right)},
$$

where $\widehat{C A R}_{i,\left(\tau_{1}, \tau_{2}\right)}$ is the cumulative abnormal return from $\tau_{1}$ to $\tau_{2}$ with a standard deviation of $\hat{\sigma}_{i,\left(\tau_{1}, \tau_{2}\right)}$. In particular, $\widehat{A R}_{i, \tau} \equiv \gamma^{\prime} \hat{\epsilon}_{i}^{*}$, where $\gamma$ is $\left(L_{2} \times 1\right)$ with one in a position $\tau_{1}-T_{1}$ to $\tau_{2}-T_{1}$ and $\hat{\sigma}_{i,\left(\tau_{1}, \tau_{2}\right)} \equiv \gamma^{\prime} \mathbf{V}_{i} \gamma$.

Let $N$ be the number of announcements. Then $\overline{\operatorname{SCAR}}_{\left(\tau_{1}, \tau_{2}\right)}=\frac{1}{N} \widehat{\operatorname{SCA}} R_{i,\left(\tau_{1}, \tau_{2}\right)}$ is normally distributed in large samples with a mean of zero and a variance of $\left(L_{1}-2\right) /\left(N\left(L_{1}-4\right)\right)$; therefore, the null hypothesis can be tested using

$$
J^{S C A R}=\left(\frac{N\left(L_{1}-4\right)}{\left(L_{1}-2\right)}\right)^{\frac{1}{2}} \overline{S C A R}_{\tau} \sim N(0,1) .
$$

Similarly, we may calculate a test statistic for standardized non-cumulative abnormal returns at time $\tau$ :

\footnotetext{
${ }^{2}$ We thank an anonymous referee for pointing this out.

${ }^{3}$ When applying the constant mean model, technically we assume that $\mathbf{R}_{m}$ and $\mathbf{R}_{m}^{*}$ are $\left(L_{1} \times 1\right)$ and $\left(L_{2} \times 1\right)$ vectors with zeros only.
} 


$$
J^{S A R}=\left(\frac{N\left(L_{1}-4\right)}{\left(L_{1}-2\right)}\right)^{\frac{1}{2}} \overline{S A R}_{\tau} \sim N(0,1),
$$

where $\overline{S A R}_{\tau}=\frac{1}{N} \widehat{S A R}_{i, \tau}$ and $\widehat{S C A} R_{i, \tau}=\widehat{C A R}_{i, \tau} / \hat{\sigma}_{i, \tau}$.

A nonparametric test statistic is also available [see, e.g., Campbell et al. (1998, pp. 172-173)], but this parametric test seems to be more commonly used in the current literature.

\section{Results}

\subsection{Market reactions to initial announcements: standardized abnormal returns}

As stated above, our final sample of 369 announcements comprised 176 initial announcements. The following figures show how standardized aggregated abnormal returns $\left(J^{S A R}\right)$ behaved around initial announcements (Fig. 1) with 95 and $99 \%$ confidence intervals.

As Fig. 1 clearly shows, investors respond to initial announcements within the first $10 \mathrm{~min}$. We refer to this 10 -min reaction "immediate reaction". Moreover, the immediate reaction is clearly negative and statistically very significant (the twosided probability of the SAR of $-10.86 /+10.86$ is $1.7875 \mathrm{e}-27)$. Thus, the results statistically support Hypothesis 1. Our data shows that negative returns are more common and are even of higher magnitude than positive returns. These results support most of the findings in the extant literature that highlights negative market reactions (Worrell et al. 1991; Lee 1997; Hallock 1998; Chen et al. 2001; Nixon et al. 2004; Capelle-Blancard and Couderc 2006; Hillier et al. 2007).

Moreover, according to Fig. 1, there are additional observations on abnormal returns with statistical significance that followed the initial announcements. These shocks can reflect investors' delayed reactions as investors may fail to assimilate all the available information immediately, or alternatively, the shocks can simply be based on the announcement of other public information that is unrelated to the published layoff announcement. ${ }^{4,5}$ Moreover, it is good to remember that if the confidence interval is $99 \%$, then, statistically, one of 100 observations should be outside the interval, on average, even if no information on layoff announcements is used.

Although, on average, not many exceptionally statistically significant returns (positive or negative) appeared after the first $10 \mathrm{~min}$, Table 1 indicates that the test

\footnotetext{
${ }^{4}$ In practice, it is impossible to filter out all the public news arrivals, whether they are company-level or macro-level news, and therefore, the existence of other information shocks cannot be ruled out in event studies.

5 It is also good to understand why these reactions cannot be spotted in Fig. $2 \mathrm{~b}$ that shows the statistics for cumulative abnormal returns. In particular, this is because the statistic $J^{S C A R}$ is normalized by an additive return variance meaning that the variance of the two-period cumulative return is twice as large as the variance of the one-period return.
} 


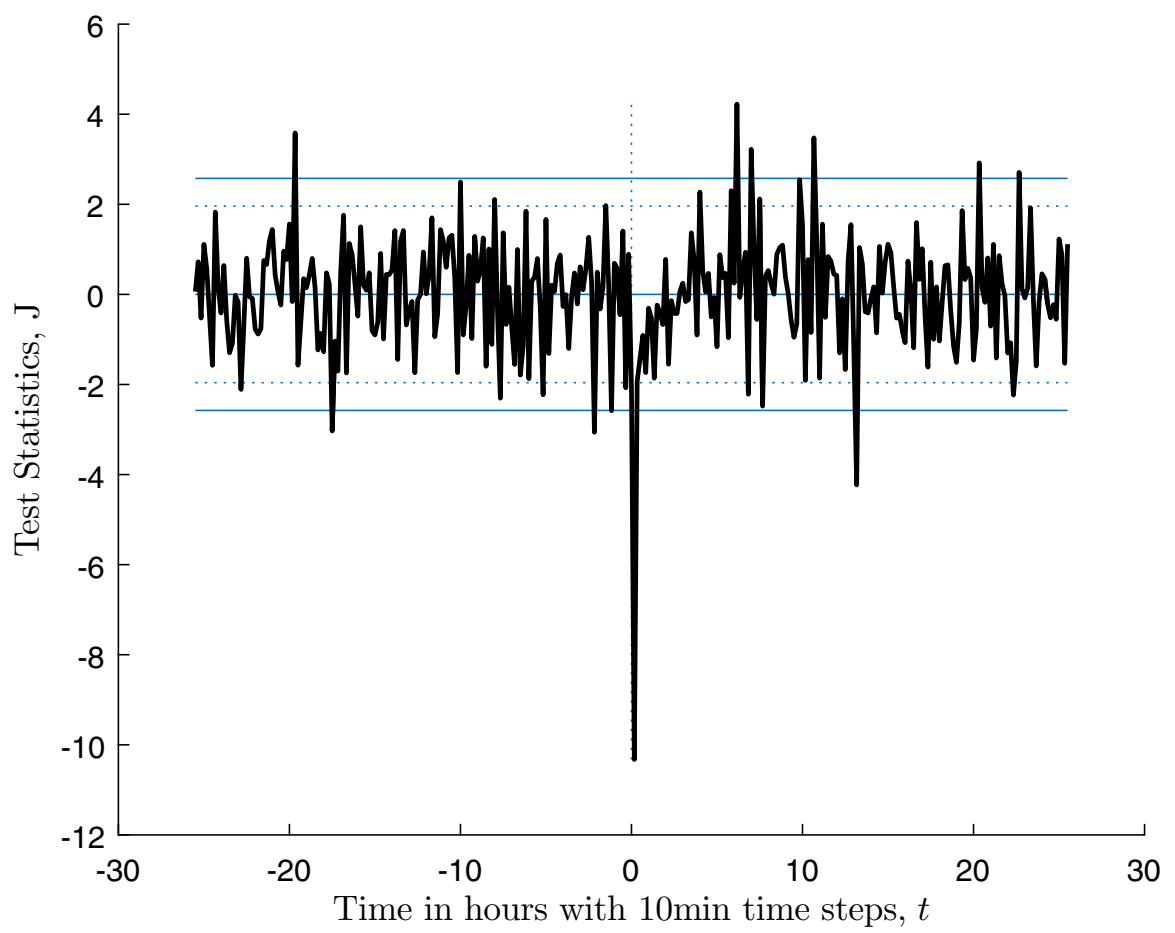

Fig. 1 Statistic $J^{S A R}$ for the standardized average abnormal return at around the initial announcement of layoffs at the $95 \%$ (dashed line) and $99 \%$ (solid line) confidence intervals. Initial announcements totaled 176. The announcement time is 0 . The length of the event window is a total of three trading days $(8.5$ trading hours in a day)

Table 1 Means and variances of test statistics $J^{S A R}$ from eight-hour periods (around 48 observations with 10-min observations) before and after layoff announcements

Prior interval $[-48 \ldots 0]$

Posterior interval [2 ... 48]

$\begin{array}{lcc}\text { Initial announcement } & & \\ \text { Mean } & 0.017 & 0.0417 \\ \text { Variance } & 1.308 & 1.4862 \\ \text { Final decision } & & \\ \text { Mean } & 0.1677 & -0.018 \\ \text { Variance } & 1.5373 & 1.5257\end{array}$

The observation from the first $10 \mathrm{~min}$ is not included to exclude the immediate reaction

statistic, $J^{S A R}$, which should be normally distributed with variance 1 and mean zero under null hypotheses, has higher variance before and after an announcement than under normal conditions. The mean of $J^{S A R}$ is clearly negative in the prior period but is close to zero in the posterior interval. In the table, the means and variances were calculated from the last and following $8 \mathrm{~h}$, not including observations from the first $10 \mathrm{~min}$ after announcements. Therefore, Table 1 shows evidence that markets 
process information on layoff announcements not only after but also before announcement periods because abnormal returns are more volatile when compared to the estimation periods. On the other hand, this paper somewhat supports the efficient market hypothesis: Prices instantly change to reflect new public information that is mainly incorporated in prices within the first minutes.

\subsection{Market reactions to initial announcements: standardized cumulative abnormal returns}

Figure 2 demonstrates how the statistic for standardized cumulative abnormal returns, $J^{S C A R}$, evolves before and after initial announcements with the 95 and $99 \%$
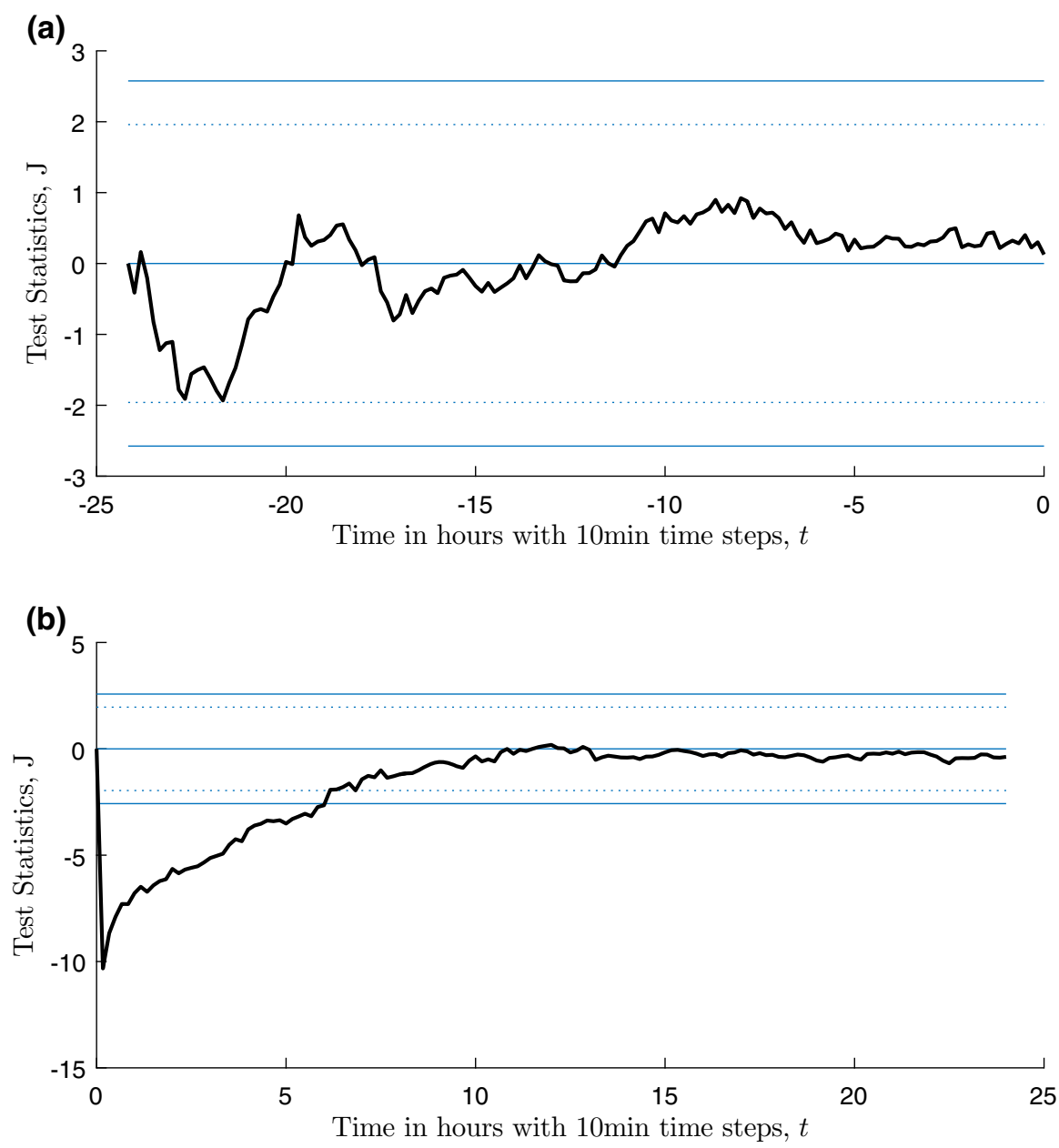

Fig. 2 Statistic $J^{S C A R}$ for the standardized cumulative average abnormal return before (a) and after (b) the initial announcements of layoffs at the $95 \%$ (dashed line) and $99 \%$ (solid line) confidence levels with 10-min time steps. Initial announcements totaled 176. The announcement time is 0 . The length of the event window is a total of three trading days (8.5 trading hours in a day). SCAR is reset in plot (b) 
confidence intervals. Plot A shows that the statistic does not hit the $99 \%$ confidence level before the announcements, meaning that the markets did not clearly anticipate the announcements on the aggregated level. However, things look very different after the announcements in Plot B. In particular, the statistic drops sharply just after the announcement during the first $10 \mathrm{~min}$, which means that the first market reaction is very strong and the confidence level of $99 \%$ is clearly exceeded, being consistent with the downward peak in Fig. 1 at time zero. ${ }^{6}$ Second, and perhaps even more importantly, after the first reaction, the test statistic, $J^{S C A R}$, drifts to its original level so that the overall cumulative effect of initial announcements over $8-10 \mathrm{~h}$ is negligible. We refer to this upward post-drift "intra-day post-reversal effect".

This phenomenon on the "immediate reaction" and the "intra-day post-reversal effect" is interesting from the point of view of information processing and market efficiency. First, although the investors' first reaction is strong and negative, they may fail to fully transfer information on layoff announcements to the stock prices during the first $10 \mathrm{~min}$, and the longer they process the published information, the less negative it looks. Alternatively, it is possible that at least a portion of the price response to new information is delayed by different investors. In other words, it might be possible that some investors immediately sell stocks after the announcements, causing a downward jump, after which other investors consider this an overreaction resulting in the recovery of the stock prices.

In the intra-day literature, short-lived effects have been identified and considered to be important even if they are not long lasting. For example, Grant et al. (2005) consider intra-day price reversals in the US stock index futures market at the market open and find highly statistically significant intra-day price reversals over a 15-year period. Additionally, Madhavan (2012), Menkveld and Yueshen (2013), Andersen and Bondarenko (2014), and Kirilenko et al. (2015) elaborate on markets' intra-day dynamics around the Flash Crash. Regarding long-term reversals, there is a phenomenon identified after earnings announcements that is known as postearnings-announcement drift (see Bernard and Thomas 1989): cumulative abnormal returns drift in the direction of an announcement after an information arrival. Whereas a layoff intra-day reversal is about overreaction and lasts one day, a postearnings-announcement drift is about under-reaction and can last several weeks or even months. However, in both cases, information content is not directly incorporated into efficient market prices. According to Bernard and Thomas (1989), the delay in post-earnings-announcement drift might occur either because traders fail to assimilate available information or because certain costs exceed gains from the immediate exploitation of information for a sufficiently large number of traders. This explanation can also be potentially used with layoff intra-day reversal, too. In particular, this failing of assimilation may be due to high costs in information processing as a result of the soft or qualitative character of the announcement (Engelberg 2009). Whereas "hard information" is easy to process (e.g., the information on income statements that follows a standardized template), "soft information" is often communicated in text, as in the case of layoff announcements.

\footnotetext{
${ }^{6}$ In fact, $\operatorname{SCAR}(0,1)$ is mathematically (and numerically) the same as $\operatorname{SAR}(1)$.
} 
From the point of view of market efficiency, this data suggests potential statistical arbitrage. In particular, on the aggregated level, investors could earn abnormally large returns by buying shares of stocks just after the first negative reaction to initial layoff announcements and selling them back at a higher price when the prices have returned to the original level. These findings are in line with the view in behavioral finance that expects a systematic overreaction to news by investors (Ball and Bartov 1996), and could represent investment opportunities as other studies have shown-even early ones as stated by Basu (1977).

For a robustness check, we also performed an analysis with daily data. As demonstrated in Fig. 2, the overall cumulativeeffect of initial announcements over $8-10 \mathrm{~h}$ is negligible, which suggests that the results can show insignificancy when the effects of the initial announcements are analyzed using only daily data (daily close prices). Figure 3 shows SCARs based on daily returns. Importantly, no statistically significant effects can be observed with daily data. This analysis emphasizes the importance of the use of intra-day data: The reactions can be shortlived but strong and are identifiable only with intra-day data. Therefore, if the use of daily data yields statistically insignificant results, it does not mean that markets do not react to news arrivals. The lack of statistically significant results can be a result of a systematic intra-day announcement reversal effect.

Overall, although informed investors seem to react to the news arrivals on initial layoff announcements immediately within the first $10 \mathrm{~min}$, it takes several hours to complete the assessment of value consequences as investors are updating their beliefs and re-running their (mathematical or mental) valuating models. Therefore, even with the use of intra-day data, one must analyze the data with relatively long time-windows (2-3 days) as done in Figs. 1 and 2. This intra-day post-reversal effect, demonstrated in Fig. 2b, is the main result of the paper. Although it is shortlived and cannot be observed using daily data (Fig. 3b), this effect is nevertheless a strong and statistically validated effect.

\subsection{Market reactions to final decisions}

The data sample comprised 193 final decisions related to previously announced layoffs. The intra-day effects of these final decisions are presented in Fig. 4 that plots the statistic for standardized aggregated abnormal returns $\left(J^{S A R}\right)$. The announcement of a final decision conveys no useful information for stock market participants as $J^{S A R}$ does not show statistical significance around time zero with the $99 \%$ confidence level but shows slight statistical significance at the $95 \%$ confidence level. On the other hand, the variance of $J^{S A R}$ plotted in Fig. 4 is about 1.55 , which means that the statistic is more volatility in an event window in comparison to the estimation window, and if $J^{S A R}$ is scaled to have the variance of one, then it does not hit $95 \%$ confidence level anymore. Overall, our results do not provide strong evidence against Hypothesis 3.

At the same time, one can observe abnormally high returns around 18, 9, and $4 \mathrm{~h}$ before the arrival of final decisions, suggesting a potential pre-reaction to the forthcoming news. This can be observed better from Fig. 5, which presents the 

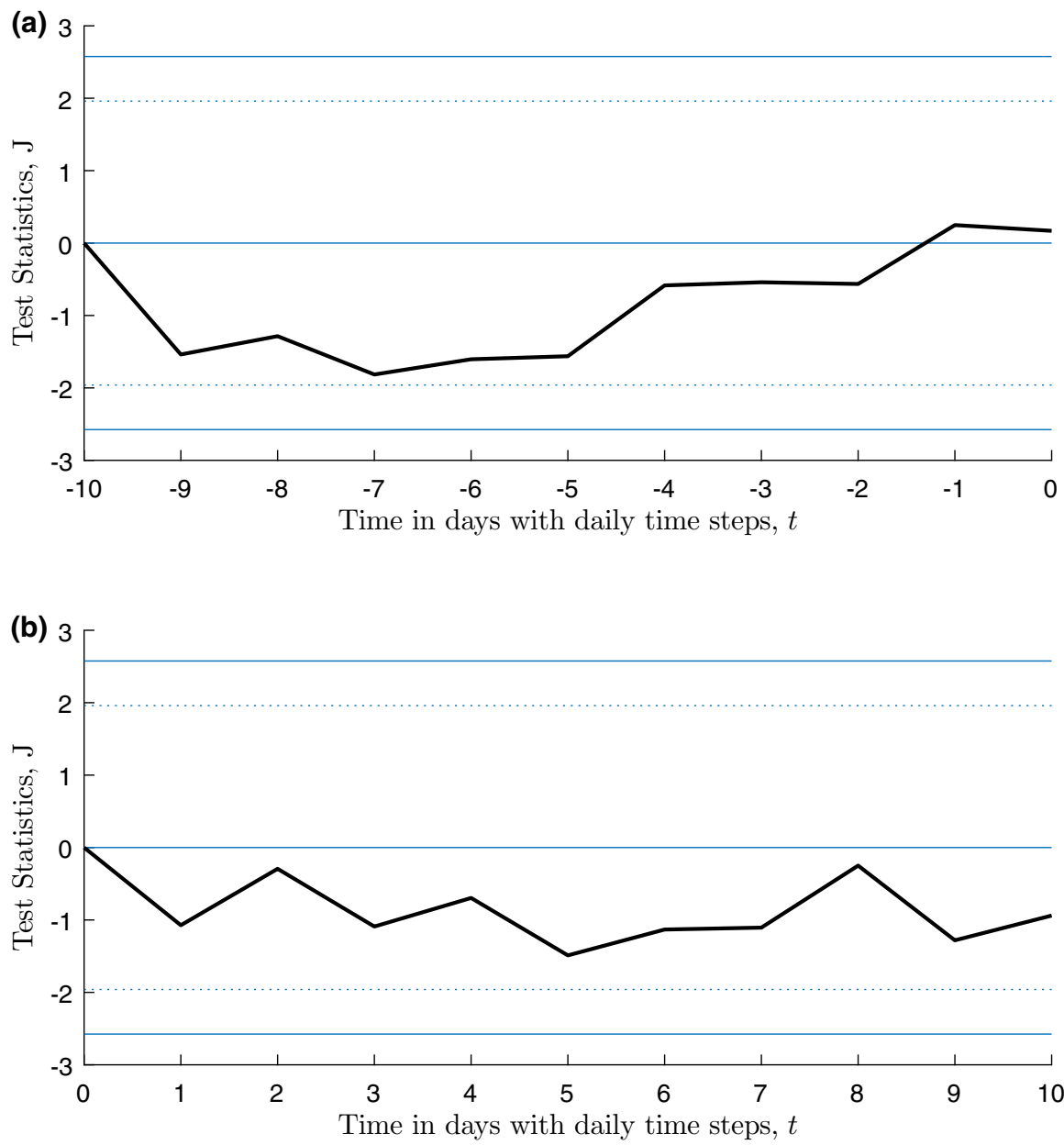

Fig. 3 Statistic $J^{S C A R}$ for the daily standardized cumulative average abnormal return before (a) and after (b) the initial announcements of layoffs at the $95 \%$ (dashed line) and $99 \%$ (solid line) confidence intervals with 10 -min time steps. Initial announcements totaled 161 . The announcement time is 0 . SCAR is reset in plot (b)

statistic for standardized cumulative abnormal returns, $J^{S C A R}$, with 99 and $95 \%$ confidence intervals before (Panel A) and after the announcement time (Panel B). In particular, $J^{S C A R}$ hits the confidence level around $11 \mathrm{~h}$ before the arrival of final decisions, indicating that the preceding cumulative returns are at an abnormally high level. Panel B shows a statistically significant immediate reaction at the $95 \%$ confidence level but no positive or negative post-drift.

Overall, the results suggest that final decisions do not make big surprises and are largely priced before the public arrivals. The possibility of information leakage has been noted in other studies (Franz et al. 1998; Chatrath et al. 1995; Brookman et al. 2007). Additionally, Lee (1997) questioned if large shareholders in Japan can 


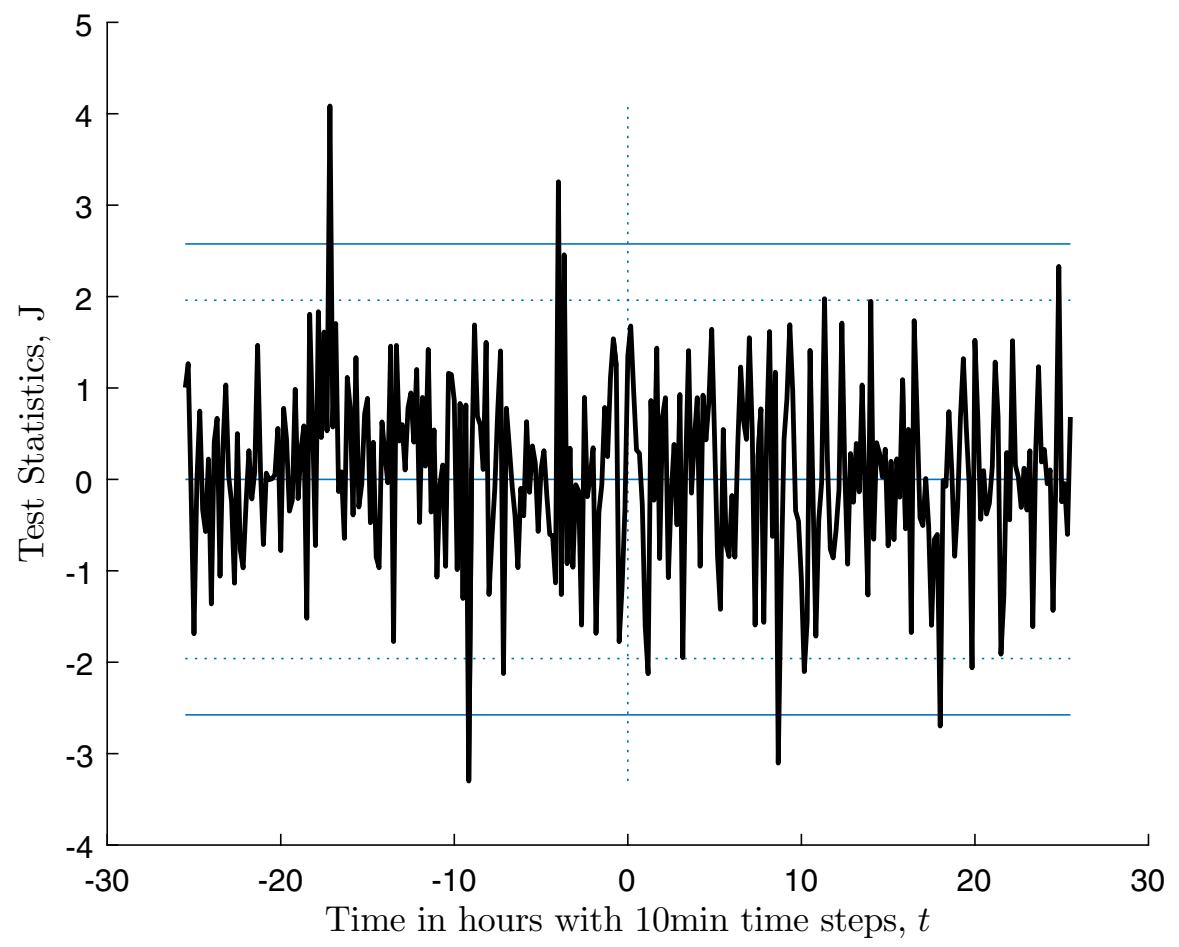

Fig. 4 Statistic $J^{S A R}$ for the standardized average abnormal return at around final layoff decisions at the $95 \%$ (dashed line) and $99 \%$ (solid line) confidence intervals. Final decisions totaled 193. The length of the event window is totally three trading days ( 8.5 trading hours in a day). The announcement time is 0

respond to layoff announcements beforehand because they may have access to relevant information before the news is made public. Lee's results, however, provide no evidence of information leakage. Moreover, Lin and Rozeff (1993), who studied pre-event reactions, argue that the market may anticipate a layoff and a temporary closing of operations if it learns about a decreasing demand affecting a firm. In addition, Worrell et al. (1991, p. 674), who also found statistically significant negative market reactions immediately before the announcements, state that "preannouncement negative market reactions appear likely to occur when leakage precedes an announcement, and announcements of large or permanent layoffs elicit stronger negative shareholder responses than announcements of small, temporary layoff". Goins and Gruca (2008) state that companies may leak their intention to perform a layoff months before a formal announcement.

Finally, Fig. 6 plots $J^{S C A R}$ by using daily close prices around final decisions. Similarly to the initial announcements, no statistically significant results can be observed with daily returns. Moreover, the use of intra-day data can provide very different insights into the markets' first reactions when compared to daily data: Whereas the first observation of intra-day $(10 \mathrm{~min}) J^{S C A R}$ is positive and statistically 

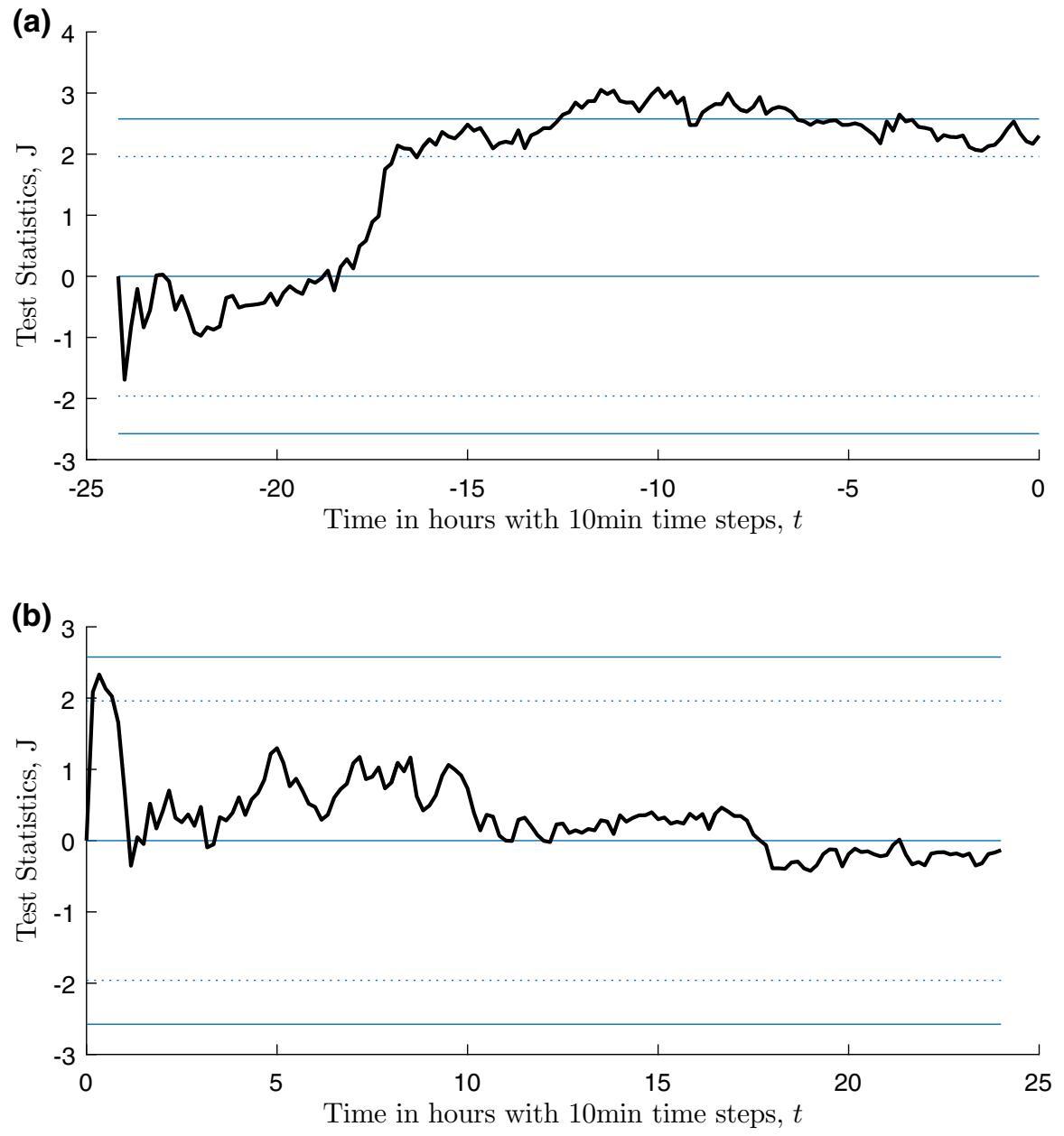

Fig. 5 Statistic $J^{S C A R}$ for the standardized cumulative average abnormal return before and after the final decisions of layoffs at the $95 \%$ (dashed line) and $99 \%$ (solid line) confidence intervals with 10-min time steps. Initial announcements totaled 193. The announcement time is 0 . The length of the event window is a total of three trading days (8.5 trading hours in a day). SCAR is reset in plot (b)

significant at the $95 \%$ confidence interval in Fig. 5 (Panel B), the first observation on daily $J^{S C A R}$ in Fig. 6 (Panel B) is negative and statistically insignificant.

\subsection{Explanatory analysis: relationship between initial announcements and corresponding final decisions}

In certain cases, information included in the announcements (e.g., the date of the initiation of employee negotiations or the specific number of employees considered in these negotiations) allowed us to link some final announcements to their 
corresponding initial announcements. We identified a total of 98 such pairs. Thus, 173 announcements were not paired out of a total of 369. Non-paired announcements included final decisions that had initially been announced before our sample period, initial announcements whose corresponding decisions were published after our sample period, final announcements related to multiple initial announcements, announcements on non-trading hours, and announcements on marginal or no market liquidity.

In this section, we examine if the variance of a standardized abnormal return on decisions is linked to the size of standardized abnormal returns on initial announcements; that is, if a weak market reaction to an initial announcement indicates growing uncertainty about reacting to a final decision (positive or negative reaction).
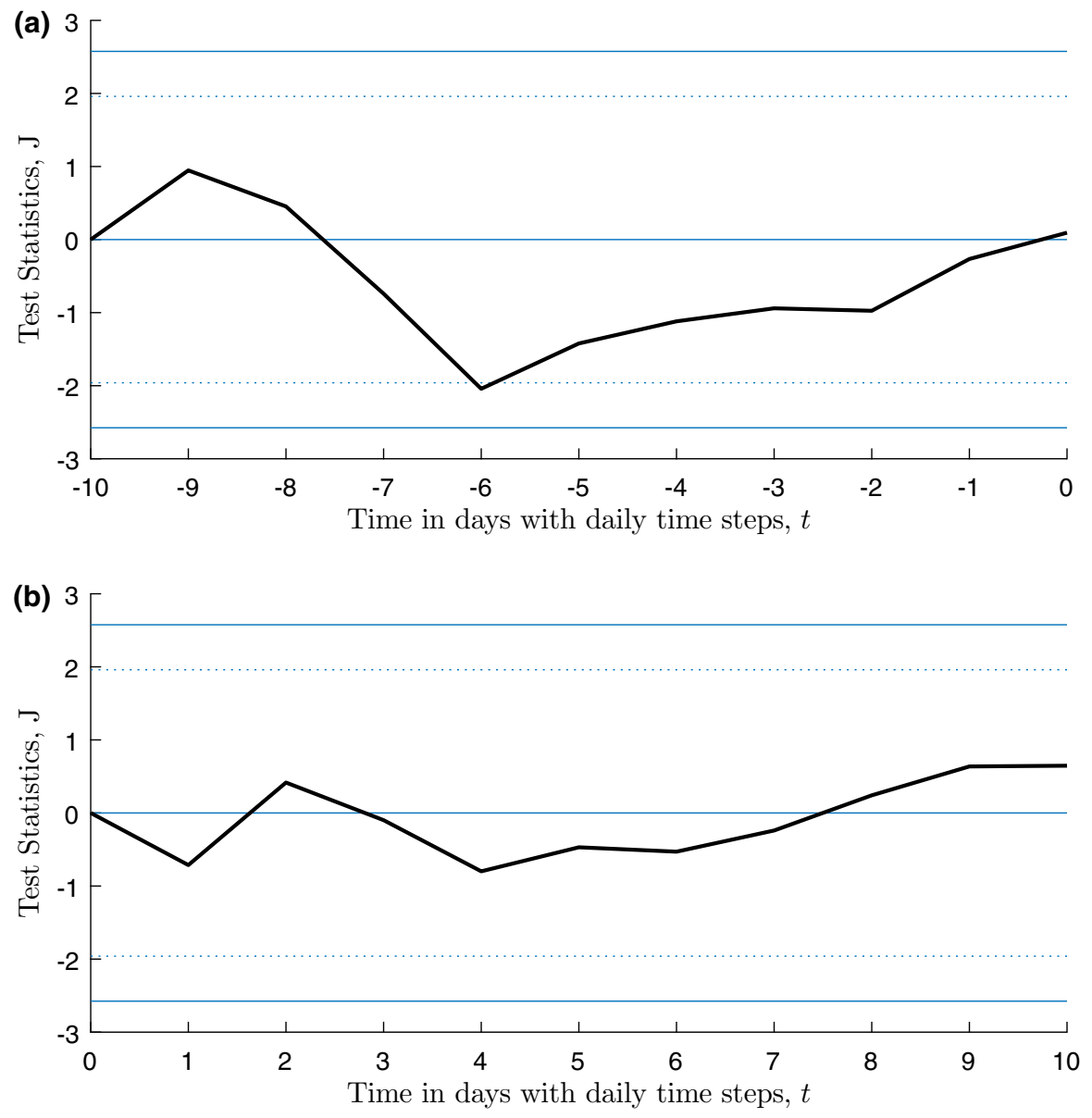

Fig. 6 Statistic $J^{S C A R}$ for the daily standardized cumulative average abnormal return before and after the final decisions of layoffs at the $95 \%$ (dashed line) and $99 \%$ (solid line) confidence intervals with 10-min time steps. Initial announcements totaled 155. The announcement time is 0. SCAR is reset in plot (b) 
We divided the pairs into two samples using the criteria that $\left|\widehat{S A R}_{i, \tau}\right|$ $\geq\left|N^{-1}(0.5+\alpha / 2)\right|$ with observations on the initial announcements' first 10-min reactions, after which the returns of the final decisions were analyzed. With $\alpha=0.05$, Sample 1 return observations after the final decisions on cases with less than $5 \%$ marginal standardized return probability on initial decisions under normal market settings (with parameters estimated from the estimation window). In other words, Sample 1 represents returns observed around final decisions in cases where there were no large reactions to initial announcements. Sample 2 comprises the other cases (i.e., returns observed around final decisions on cases where there were larger reactions to initial announcements).

The following table shows descriptive statistics and results for the Chi-square test in the two data samples (Table 2).

First, we observe that the estimated standard deviation is quite high for Sample 1 and close to one for Sample 2. This indicates that if the first reaction to an initial announcement is marginal (see the definition of Sample 1), there may be considerable uncertainty about the final decision (i.e., high standard deviation in Sample 1 around final decisions). The Chi-square test indicates that the null hypothesis that the data comes from a distribution with a variance of one can be rejected for Sample 1 (no initial reaction) but not for Sample 2 (cases with nonnegligible reactions). Therefore, if an initial layoff announcement conveys information that is not useful for stock market participants resulting in a weak initial market reaction (Sample 1), the corresponding final decision has an abnormally high variance.

In addition to a Chi-square variance test, we performed an F-test and Levene's test to compare the equality of variances in Samples 1 and 2. Results for both tests are as follows:

- For the F-test, the statistic was 6.3532 with a $p$ value of $4.50 \mathrm{e}-09$, which clearly indicates that Sample 1 has unequal (higher) variance when compared to Sample 2.

Table 2 Analysis of the relationship between initial announcements and corresponding final decisions with the identified pairs

\begin{tabular}{lll}
\hline & Sample 1 & Sample 2 \\
\hline Size & 55 & 43 \\
Mean & 0.16367 & 0.20744 \\
SD & 2.52215 & 1.00063 \\
Chi-square variance test against variance 1 & & \\
Chisqstat & 343.5057 & 42.0529 \\
$p$ (two-sided) & 0 & 0.9374 \\
\hline
\end{tabular}

The table reports the mean, standard deviation, and a Chi-square test of returns after the final decisions on Samples 1 and 2. Sample 1 comprises cases with marginal returns $(\boldsymbol{\alpha}=0.05)$ on initial returns and Sample 2 the other cases. The Chi-square statistic tests the null hypothesis that the data comes from a distribution with a variance of 1 


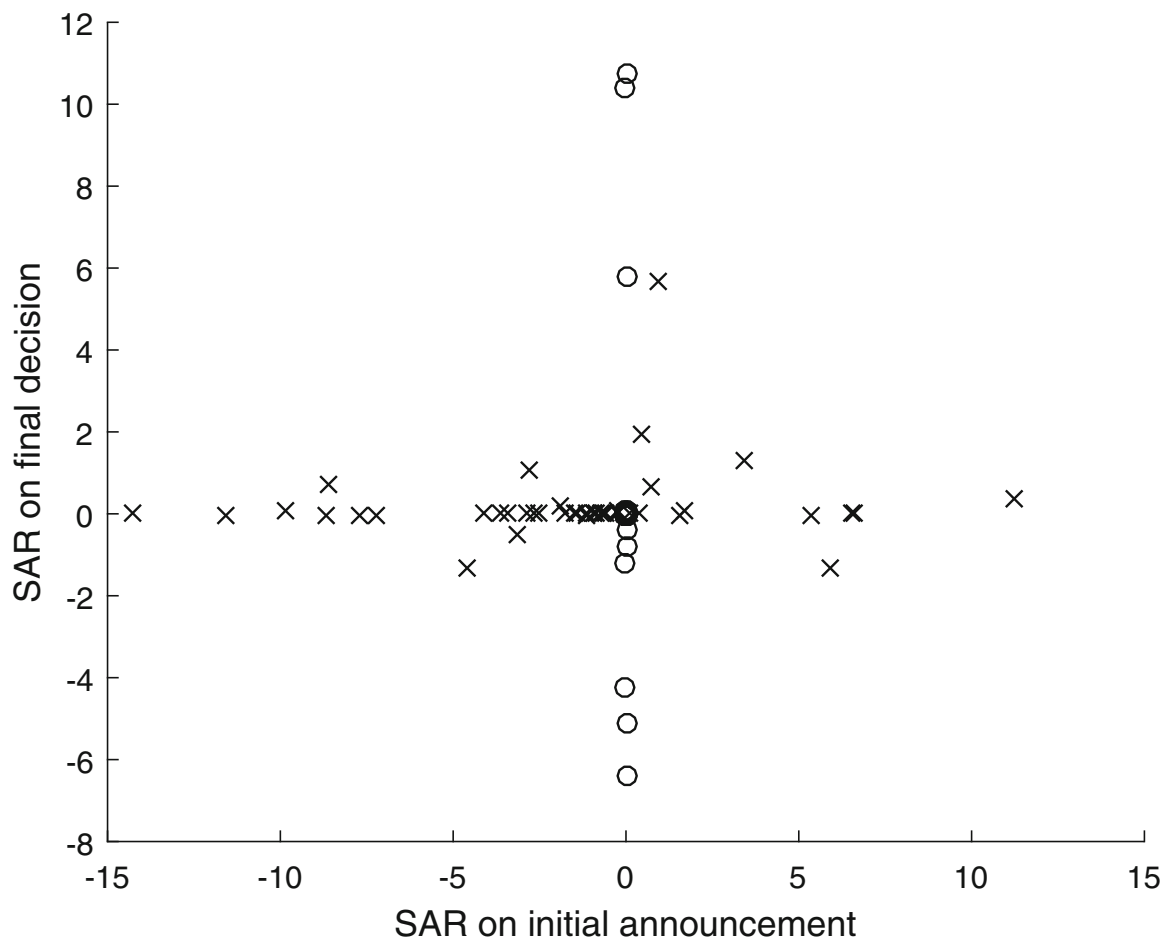

Fig. 7 A scatter plot for the pairs of initial and final decisions. 'O' represents Sample 1 with small returns around initial announcements, i.e. cases with marginal returns $(\boldsymbol{\alpha}=0.05)$ on initial returns, and ' $\mathrm{X}$ ' represents Sample 2 with larger returns around initial announcements

- However, Levene's test statistic was 2.4373, indicating a $p$ value of 0.1218 , which is substantially more than $5 \%$.

Therefore, depending on the statistical procedure, we gained strong or no evidence against the null hypothesis concerning equal sample variances: The F-test suggests that the estimated variance of standardized abnormal returns on a final decision was of a high level if the reaction to the initial announcement was negligible, but Levene's test not.

Moreover, Fig. 7 demonstrates that stock prices shift strongly after final decisions only if there had been a weak reaction to initial announcements. This is an interesting result and, to our knowledge, has not been highlighted in previous research. It suggests that although final decisions do not result in significant stock price movements, on average, investors may react to the final decision if the initial layoff announcement did not provide enough information. However, we must emphasize that because our sample was very small, this result is of little evidence and is only suggestive. Therefore, we encourage future research to confirm the finding. 


\subsection{Additional analysis: regressing SARs against background information}

As an additional analysis, we aim to explain the immediate (10-min) stock price reaction by using background data on companies' characteristics as explanatory variables. The variables capture the number of employees, net sales, operating profit, earnings before taxes, assets/liabilities and annual changes in these variables. Moreover, the number of employees considered in the negotiations is also available. To eliminate multicollinearity in the regression, we use uncorrelated principal components in regression (for the use of principal components in regression, see for example, Jolliffe 1982 and references therein).

Table 3 shows the results for principal component analysis with varimax rotation. Four components were extracted and used as independent variables in the regression analysis to explain the standardized abnormal return from the first 10 min. Each component consisted of two items with significant component loadings $(>0.7)$, and the principal component analysis yielded an appropriate factor structure, which explained the 74.312 percent of variance. Bartlett's test of sphericity was very significant and the Kaiser-Meyer-Olkin measure of sampling adequacy was 0.528 , which is slightly higher than the generally accepted threshold of 0.5. Importantly, loadings are distributed across the components in a very nice and meaningful way, which makes this approach feasible as the components have clear economic interpretations. In particular, in relation to the loadings, the components can be called "1. Profitability", "2. Size", "3. Change in Size", and "4. Change in Profitability".

Table 4 presents the results of a regression analysis for initial announcements, where the explained variable is the standardized abnormal return from the first $10 \mathrm{~min}$ and the independent variables are the principal components (see Table 3). Moreover, as suggested by Farber and Hallock (2009), our study identified five reasons disclosed with layoff announcements, namely, (i) reorganization, (ii) plant

Table 3 Principal component analysis (rotated component matrix with varimax rotation); loadings above the threshold 0.7 are in bold

\begin{tabular}{|c|c|c|c|c|}
\hline \multirow[t]{2}{*}{ Original variable } & \multicolumn{4}{|l|}{ Component } \\
\hline & 1. "Profitability" & 2. "Size" & $\begin{array}{l}\text { 3. "Change } \\
\text { in Size" }\end{array}$ & $\begin{array}{l}\text { 4. "Change in } \\
\text { Profitability" }\end{array}$ \\
\hline Number of employees & 0.257 & 0.852 & -0.050 & 0.036 \\
\hline Change in number of employees & -0.022 & -0.012 & 0.976 & -0.015 \\
\hline Net sales & 0.405 & 0.826 & -0.041 & -0.024 \\
\hline Change in net sales & 0.070 & -0.043 & 0.974 & 0.042 \\
\hline Operating profit & 0.970 & 0.125 & 0.026 & 0.032 \\
\hline Change in operating profit & -0.002 & 0.110 & 0.031 & 0.745 \\
\hline EBT & 0.974 & -0.009 & 0.028 & 0.037 \\
\hline Change in EBT & 0.024 & -0.091 & 0.000 & 0.763 \\
\hline Asset/liabilities & 0.129 & -0.410 & -0.040 & 0.268 \\
\hline Number of employees under lay off & -0.299 & 0.656 & -0.033 & 0.175 \\
\hline
\end{tabular}


Table 4 Results of regression analysis of initial announcements

\begin{tabular}{|c|c|c|c|c|c|}
\hline Variable & Coefficient & $\begin{array}{l}\text { Std. } \\
\text { error }\end{array}$ & $\begin{array}{l}\text { Standardized } \\
\text { coefficient }\end{array}$ & $t$ & Sig. \\
\hline Constant & -0.856128 & 0.292223 & & -2.92971 & 0.003938 \\
\hline 1. Component "Profitability" & 0.19210491 & 0.239497 & 0.067014853 & 0.802117 & 0.423789 \\
\hline 2. Component "Size" & -0.3354054 & 0.262156 & -0.105526098 & -1.27941 & 0.202782 \\
\hline 3. Component "Change in Size" & -0.0346369 & 0.260985 & -0.010860345 & -0.13272 & 0.894601 \\
\hline $\begin{array}{l}\text { 4. Component "Change in } \\
\text { Profitability" }\end{array}$ & 0.18453009 & 0.25718 & 0.059808819 & 0.717514 & 0.474203 \\
\hline $\begin{array}{l}\text { Reason indicator: } 1 \text { if } \\
\text { reorganization, } 0 \text { otherwise }\end{array}$ & 0.48126251 & 0.769292 & 0.052821676 & 0.625592 & 0.53256 \\
\hline
\end{tabular}

Independent variables: principal components. Dependent variable: SAR from the first $10 \mathrm{~min}$

Table 5 Results of regression analysis of final decisions

\begin{tabular}{|c|c|c|c|c|c|}
\hline Variable & Coefficient & $\begin{array}{l}\text { Std. } \\
\text { error }\end{array}$ & $\begin{array}{l}\text { Standardized } \\
\text { coefficient }\end{array}$ & $t$ & Sig. \\
\hline Constant & 0.09826862 & 0.223697 & & 0.439294 & 0.661041 \\
\hline 1. Component "Profitability" & 0.23860403 & 0.24536 & 0.077327838 & 0.972464 & 0.332288 \\
\hline 2. Component "Size" & 0.14733002 & 0.217226 & 0.054116572 & 0.678234 & 0.498603 \\
\hline 3. Component "Change in Size" & -0.0536254 & 0.209605 & -0.020061866 & -0.25584 & 0.798403 \\
\hline $\begin{array}{l}\text { 4. Component "Change in } \\
\text { Profitability" }\end{array}$ & -0.0565761 & 0.218643 & -0.020428725 & -0.25876 & 0.796153 \\
\hline $\begin{array}{l}\text { Reason indicator: } 1 \text { if } \\
\text { reorganization, } 0 \text { otherwise }\end{array}$ & 0.55556422 & 0.566164 & 0.07728064 & 0.981277 & 0.327938 \\
\hline
\end{tabular}

Independent variables: principal components. Dependent variable: SAR from the first $10 \mathrm{~min}$

closing, (iii) demand slump, (iv) cost issues/respond to decreased profitability, and (v) other, unknown reasons. Farber and Hallock (2009) found that layoff announcements citing reorganization as the main driver have significantly greater average abnormal returns (by 0.51 percentage points). Therefore, we created a binary variable with 1 for reorganization and 0 otherwise and used it as a dummy variable. ${ }^{7}$ Table 5 shows the corresponding results for final decisions.

Results in Tables 4 and 5 show that whereas the constant coefficient is statistically very significant for initial announcements and consistent with the $J$ statistic in Fig. 1, it is clearly statistically insignificant for final decisions (see Fig. 2). Moreover, in both cases the independent variables (principal components) are not linked with the first reaction (SAR on the first $10 \mathrm{~min}$ ). This means that the financial data or the number of employees facing negotiations is not linked with market reactions to initial layoff announcements or final decisions. In addition, the dummy variable is statistically insignificant and suggests that no statistically significant relationship exists between reasons stated for layoffs and the market

\footnotetext{
$\overline{7}$ The use of four dummy variables would lead to too small sample sizes for some categories.
} 
reaction. These results support for example Marshall et al. (2012) and Farber and Hallock (2009) and indicate that company background characteristics are not statistically related to a stock market reaction to layoff announcements. Our results also simultaneously contradict other papers (Chatrath et al. 1995; Palmon et al. 1997; Elayan et al. 1998; Chalos and Chen 2002; Capelle-Blancard and Couderc 2006). Therefore, our results provide strong evidence against Hypothesis 4.

\section{Conclusions}

This study is the first to evaluate the effect of employee layoff announcements on market returns using intra-day market data. Altogether, 369 announcements by 80 companies were scrutinized, and the stock price reactions to these announcements were analyzed by calculating the cumulative abnormal returns. Using intra-day data, we analyzed the reactions that occurred in the first minutes after the announcements.

Various conclusions can be drawn from our study. First, on average, stock markets immediately react negatively and strongly to initial layoff announcements with statistical significance (supports Hypothesis 1). However, the first reaction, which is immediate and strong, retracts during the following hours showing no longterm persistence (supports Hypothesis 2). In fact, the processing of the initial announcements seems to take several hours as investors probably are updating their beliefs and completing the assessment of the consequences of the announcements.

Second, final decisions seem to convey no useful information for investors, suggesting that a final decision is predictable and already priced before its announcement (supports Hypothesis 3). Another possibility is an information leak before the announcement is made public. Consequently, final decisions do not seem to drive stock prices, a finding that supports the common practice of focusing only on the first announcement. Third, our results did not highlight any statistically significant relationship between firm characteristics (e.g., number of employees, net sales, operating profit, EBT, EBTR, total assets, industry) and the sign/magnitude of market reactions. Similarly, no statistically significant relationship was found between the sign/magnitude of stock price reactions and reasons for layoffs in announcements (Hypothesis 4 not supported).

Moreover, for the initial announcement and its corresponding final decision (i.e., the pairs), if the initial announcement conveys information that is not useful for stock valuation, then the final decision may greatly affect stock returns. Conversely, if the initial announcement conveys information useful for stock valuation, then the final decision may only marginally affect stock returns. This is an interesting result and suggests that although reactions to final decisions are not statistically significant on the aggregated level, investors may react to final decisions if they did not react to the initial announcements.

Our work has answered the call for more research on downsizing and its consequences (Cascio et al. 1997; Datta et al. 2010). Future research could take note of the methodology used in our study. With intra-day data, we were able to identify the market reactions that are not present when analyses are conducted with daily closing prices. There may be various phenomena leading to these results, including 
the nature of formation of closing prices, dilution of reactions in time, informationprocessing. Importantly, we showed that with intra-day data we can find immediate reactions to complex information that are then revised in the following hours, potentially driven by information post-processing. This result may provide clues for future research on detecting reactions to other events as well. Moreover, future research could take note of the methodology used in this paper and draw on intraday data to analyze layoff announcements in other economic and geographic scenarios. In addition, the effects of employee reduction on market returns make for an interesting and insightful research topic. For example, researchers could follow the suggestion of Oxley et al. (2009) and analyze the effects of layoff announcements on the abnormal returns of rival companies. In this context, it would be interesting to study if layoff announcements are linked to attenuation or enhancement of competition.

Last, this paper has some limitations. Our sample of pairs (formed of the initial announcements and related final decisions) was small in comparison to the total sample. Therefore, future research could consider larger announcement samples to compile a statistically more robust sample of pairs. Moreover, some authors (Farber and Hallock 2009; Marshall et al. 2012) have noted that markets tend to react negatively or positively to layoff announcements depending on the prevailing economic conditions (booms or recessions). The data in this study comprises mostly market reactions during the housing bubble recession that started in 2008. Therefore, future studies that use intra-day data could consider and compare layoff announcements during economic booms and depressions.

Open Access This article is distributed under the terms of the Creative Commons Attribution 4.0 International License (http://creativecommons.org/licenses/by/4.0/), which permits unrestricted use, distribution, and reproduction in any medium, provided you give appropriate credit to the original author(s) and the source, provide a link to the Creative Commons license, and indicate if changes were made.

\section{References}

Aït-Sahalia Y, Mykland PA, Zhang L (2005) How often to sample a continuous-time process in the presence of market microstructure noise. Rev Financ Stud 18(2):351-416

Andersen TG, Bondarenko O (2014) VPIN and the flash crash. J Financ Mark 17:1-46

Ball R, Bartov E (1996) How naive is the stock market's use of earnings information. J Account Econ 21(3):319-337

Basu S (1977) Investment performance of common stocks in relation to their price-earnings ratios: a test of the efficient market hypothesis. J Finance 32(3):663-682

Bernard VL, Thomas JK (1989) Post-earnings-announcement drift: delayed price response or risk premium? J Account Res 27:1-36

Bollerslev T, Chou RY, Kroner F (1992) ARCH modeling in finance: a review of the theory and empirical evidence. J Economet 52(1):5-59

Brookman JT, Chang S, Rennie CG (2007) CEO cash and stock-based compensation changes, layoff decisions, and shareholder value. Financ Rev 42(1):99-119

Campbell JY, Lo AW, MacKinlay AC, Whitelaw RF (1998) The econometrics of financial markets. Macroecon Dyn 2(4):559-562

Capelle-Blancard G, Couderc N (2006) How do shareholders respond to downsizing? A meta-analysis. A meta-analysis. SSRN: http://ssrn.com/abstract=952768 
Cascio WF (1993) Downsizing: what do we know? What have we learned? Acad Manag Exec 7(1):95-104

Cascio WF, Young CE, Morris JR (1997) Financial consequences of employment-change decisions in major US corporations. Acad Manag J 40(5):1175-1189

Chalos P, Chen CJ (2002) Employee downsizing strategies: market reaction and post announcement financial performance. J Bus Finance Account 29(5-6):847-870

Chatrath A, Ramchander S, Song F (1995) Are market perceptions of corporate layoffs changing? Econ Lett 47(3):335-342

Chen P, Mehrotra V, Sivakumar R, Yu WW (2001) Layoffs, shareholders' wealth, and corporate performance. J Empir Finance 8(2):171-199

Cornfield DB (1983) Chances of layoff in a corporation: a case study. Adm Sci Q 28(4):503-520

Corrado CJ (2011) Event studies: a methodology review. Account Finance 51:207-234

Datta DK, Guthrie JP, Basuil D, Pandey A (2010) Causes and effects of employee downsizing: a review and synthesis. J Manag 36(1):281-348

De Meuse KP, Vanderheiden PA, Bergmann TJ (1994) Announced layoffs: their effect on corporate financial performance. Hum Resour Manag 33(4):509-530

De Meuse KP, Bergmann TJ, Vanderheiden PA, Roraff CE (2004) New evidence regarding organizational downsizing and a firm's financial performance: a long-term analysis. J Manag Issues 16(2): 155-177

Dolley JC (1933) Characteristics and procedure of common stick split-ups. Harv Bus Rev 11:316-326

Elayan FA, Swales GS, Maris BA, Scott JR (1998) Market reactions, characteristics, and the effectiveness of corporate layoffs. J Bus Finance Account 25(3-4):329-351

Engelberg J (2009) Costly information processing: evidence from earnings announcements (January 18, 2008). AFA 2009 San Francisco meetings paper. SSRN: http://ssrn.com/abstract=1107998 or doi:10. 2139/ssrn. 1107998

Engle RF, Bollerslev T (1986) Modelling the persistence of conditional variances. Economet Rev 5(1): $1-50$

Farber HS, Hallock KF (2009) The changing relationship between job loss announcements and stock prices: 1970-1999. Labour Econ 16(1):1-11

Ferguson NJ (2015) Investor information processing and trading volume. Asia-Pac J Financ Stud 44:322-351

Franz DR, Crawford D, Dwyer DJ (1998) Downsizing, corporate performance, and shareholder wealth. Am J Bus 13(1):11-20

Goins S, Gruca TS (2008) Understanding competitive and contagion effects of layoff announcements. Corp Reput Rev 11(1):12-34

Grant JL, Wolf A, Yu S (2005) Intraday price reversals in the US stock index futures market: a 15-year study. J Bank Finance 29:1311-1327

Hallock KF (1998) Layoffs, top executive pay, and firm performance. Am Econ Rev 88(4):711-723

Hillier D, Marshall A, McColgan P, Werema S (2007) Employee layoffs, shareholder wealth and firm performance: evidence from the UK. J Bus Finance Account 34(3-4):467-494

Hoskisson RE, Hitt MA (1994) Downscoping: how to tame the diversified firm. Oxford University Press, New York

Jolliffe IT (1982) A note on the use of principal components in regression. Appl Stat 31:300-303

Ke Y (2013) Voluntary disclosure policy change and information asymmetry: evidence from firms' initiation and cessation of quarterly earnings guidance, working paper

Kirilenko et al (2015) The flash crash: the impact of high frequency trading on an electronic market, SSRN working paper

Kozlowski SW, Chao GT, Smith EM, Hedlund J (1993) Organizational downsizing: strategies, interventions, and research implications. Int Rev Ind Organ Psychol 8(8):263-332

Lee PM (1997) A comparative analysis of layoff announcements and stock price reactions in the United States and Japan. Strateg Manag J 18(11):879-894

Lee PM, O'neill HM (2003) Ownership structures and R\&D investments of US and Japanese firms: agency and stewardship perspectives. Acad Manag J 46(2):212-225

Lee CMC, Mucklow B, Ready MJ (1993) Spreads, depths, and the impact of earnings information: an intraday analysis. Rev Financ Stud 6(2):345-374

Libby T, Mathieu R, Robb SW (2002) Earnings announcements and information asymmetry: an intra-day analysis. Contemp Account Res 19(3):449-472 
Lin J, Rozeff MS (1993) Capital market behavior and operational announcements of layoffs, operation closings, and pay cuts. Rev Quant Financ Acc 3(1):29-45

MacKinlay AC (1997) Event studies in economics and finance. J Econ Lit 35(1):13-39

Madhavan A (2012) Exchange-traded funds, market structure, and the flash crash. Financ Anal J 68:20-35

Marshall A, McColgan P, McLeish S (2012) Why do stock prices decline in response to employee layoffs? UK evidence from the 2008 global financial crisis. J Financ Res 35(3):375-396

Menkveld A, Yueshen BZ (2013) Anatomy of the flash crash, SSRN working paper

Mentz M, Schiereck D (2008) Cross-border mergers and the cross-border effect: the case of the automotive supply industry. Rev Manag Sci 2(3):199-218

Mucklow B (1994) Market microstructure: an examination of the effects on intraday event studies. Contemp Acc Res 10(2):355-382

Nixon RD, Hitt MA, Lee H, Jeong E (2004) Market reactions to announcements of corporate downsizing actions and implementation strategies. Strateg Manag J 25(11):1121-1129

Oxley JE, Sampson RC, Silverman BS (2009) Arms race or détente? How interfirm alliance announcements change the stock market valuation of rivals. Manag Sci 55(8):1321-1337

Palmon O, Sun H, Tang AP (1997) Layoff announcements: stock market impact and financial performance. Financ Manag 26(3):54-68

Wayhan VB, Werner S (2000) The impact of workforce reductions on financial performance: a longitudinal perspective. J Manag 26(2):341-363

Wertheim P, Robinson M (2000) The effect of a firm's financial condition on the market reaction to company layoffs. J Appl Bus Res 16(4):63-72

Worrell DL, Davidson WN, Sharma VM (1991) Layoff announcements and stockholder wealth. Acad Manag J 34(3):662-678 